\title{
Postoperative Findings of Nausea and Vomiting: Study in a Private Clinics, Dhaka, Bangladesh
}

\author{
Dr. Mohammad Mostafizur Rahman ${ }^{1 *}$, Dr. Jannatul Ferdous ${ }^{2}$
}

${ }^{1}$ Assistant Professor, Department of Anesthesia, Shaheed Monsur Ali Medical College Hospital, Dhaka, Bangladesh

${ }^{2}$ Associate Professor, Department of Gynae \& Obstetric, Ashiyan Medical College Hospital, Barua Khilkhet, Dhaka, Bangladesh

DOI: $10.36347 /$ sjams.2020.v08i11.017

| Received: 29.10.2020 | Accepted: 10.11.2020 | Published: 14.11.2020

*Corresponding author: Dr. Mohammad Mostafizur Rahman

Abstract

Original Research Article

Introduction: Post-operative Nausea and Vomiting still remains a challenge, despite having clinical perception and evidence that its severity has diminished. We conducted a descriptive study in post the operative units in several private clinics, Pabna, Bangladesh. Aim of the study: Our aim was to find out the magnitude of postoperative nausea and vomiting in patients. Material \& Methods: This was a prospective descriptive study to estimate the incidence of postoperative nausea and vomiting. We conducted this study in post-operative units in the Department of Anesthesia, Ashiyan Medical College Hospital, Barua Khilkhet, Dhaka, Bangladesh Dhaka, and Bangladesh during the period from January 2018 to December 2018. Results: Nausea, emetic episodes and the need for anti-emetic medication were recorded for $24 \mathrm{~h}$ postoperatively. In the post-operative unit, nausea and vomiting were $27.25 \%$ and $13.25 \%$, respectively. Over the whole 24 -h period, these figures were $65.75 \%$ and $35 \%$, respectively and severe nausea was experienced by $7.88 \%$ in an average. The highest rate of emetic sequelae was observed in gynaecological patients; $42 \%$ of the patients who received general anaesthesia and $62 \%$ of the patients who received regional anaesthesia reported nausea. Conclusion: The most important predictive factors associated with an increased risk for nausea and vomiting were female gender, a previous history of postoperative sickness, a longer duration of surgery and a history of motion sickness. Even though, nausea and vomiting problem is neglected in developing world like Bangladesh but it's indeed a big problem for the patients and can hindered normal treatment procedures. Researchers should give more attention to this issue for reducing the burden of treatment facilities in our country.

Keywords: Post-operative, Vomiting, Nausea, anaesthesia.

Copyright $(\mathcal{C} 2020$ The Author(s): This is an open-access article distributed under the terms of the Creative Commons Attribution 4.0 International License (CC BY-NC 4.0) which permits unrestricted use, distribution, and reproduction in any medium for non-commercial use provided the original author and source are credited.

\section{INTRODUCTION}

Many adults find postoperative nausea and vomiting even more distressing than postoperative pain. The overall incidence of postoperative nausea and vomiting in the recovery room is around 10\% [1] but ranges from $20 \%$ to $30 \%$ during the first $24 \mathrm{~h}$ after surgery according to recent reports [1-4]. Despite the advances in modern anaesthetic practice and surgical techniques, there is still room for improvement in identifying the causative factors as well as in the prophylaxis and treatment of this problem. The assessment intervals were $0-2 \mathrm{~h}$ and $2-24 \mathrm{~h}$; the first 2 $\mathrm{h}$ spent in the recovery room and the remainder mostly on the surgical ward. The anaesthetic nurses completed the items on the surgical procedure, the premeditation and the anesthetic given. They also recorded medication for postoperative pain and possible postoperative nausea and vomiting and its treatment after the 2-h assessment in the recovery room. The questionnaire accompanied each patient's medical report to the ward.
The patients were interviewed on the first postoperative day, $24 \mathrm{~h}$ after the operation and the anesthetic records were reviewed to ensure the completeness of the collected data. All interviews were conducted by the data collectors. Before visiting the patient, the interviewer recorded data from the medical notes about pain medication, emetic episodes and anti-emetics used. During the interview, the patients were asked, in addition to their background characteristics, about the presence and intensity of nausea, vomiting and pain, any feeling of fatigue or drowsiness postoperatively and the overall satisfaction with the given treatment, including surgery, anaesthesia and postoperative care. Assessment of symptoms and their measurements Nausea was evaluated by the patient's subjective sensation of feeling sick or wishing to vomit.

\section{OBJECTIVE}

a) General objective

To observe post-operative nausea and vomiting 
b) Specific objectives

To assess key anaesthetic and surgical factors associated with these symptoms

\section{Method And Materials}

This was a prospective descriptive study to estimate the incidence of postoperative nausea and vomiting. We conducted this study in post-operative units in units in the Department of Anesthesia, Ashiyan Medical College Hospital, Barua Khilkhet, Dhaka, Bangladesh Dhaka, Bangladesh during the period from January 2018 to December 2018.. Our aim was to estimate incidence of nausea and vomiting in postoperative room. To achieve a representative sample of everyday surgery, we collected data from several types of common surgical procedures in five different private clinics in the departments of general surgical including orthopaedics, gynaecological, ophthalmological and otolaryngological. The study scheduled was to observe undergoing elective surgery requiring general or regional anaesthesia and follow-up for the first 2 hours in the recovery room and then post-operative room. Both genders were included, but pregnant patients and those requiring treatment in the intensive care unit were not studied. All patients during this period who met the inclusion criteria and gave their informed consent enrolled in the study. Anaesthetic staffs were instructed to keep records on nausea and vomiting. All statistical calculations were performed by the SPSS statistical package.

\section{RESULTS}

Questionnaires and interviews were completed for 110 patients, of whom $50(50 \%)$ were male and another $50 \%$ were females. The distribution of the inpatients within the surgical departments and different procedures is shown in the tables and figure. Nausea, emetic episodes and the need for anti-emetic medication were recorded for $24 \mathrm{~h}$ postoperatively. In the postoperative unit, nausea and vomiting were $27.25 \%$ and $13.25 \%$, respectively. Over the whole 24 -h period, these figures were $65.75 \%$ and $35 \%$, respectively and severe nausea was experienced by $7.88 \%$ in an average. The highest rate of emetic sequelae was observed in gynaecological patients; $42 \%$ of the patients who received general anaesthesia and $62 \%$ of the patients who received regional anaesthesia reported nausea. The most important predictive factors associated with an increased risk for nausea and vomiting were female gender, a previous history of postoperative sickness, a longer duration of surgery and a history of motion sickness. The highest number of vomiting episodes was three in seven patients. The highest incidence of nausea $(27 \%)$ was reported in gynaecology patients, of whom $21 \%$ were treated with anti-emetic medication. During the second observation period from 2 to $24 \mathrm{~h}$ postoperatively, the proportions of patients with nausea and vomiting in the whole population were $49 \%$ and $24 \%$, respectively. Of all the patients reporting nausea, $49 \%$ also vomited. Severe vomiting (more than three episodes) occurred in 56 patients. Again the rates were highest in the gynaecology patients (nausea $60 \%$ and vomiting $31 \%$ ), but also half of the otolaryngological patients suffered from nausea. Among the separate types of surgery, the highest incidence of nausea appeared in gynaecological laparotomy (73\%), joint replacement $(61 \%)$ and general surgical laparoscopy (58\%); of these nauseated patients, $41 \%, 70 \%$ and $47 \%$, respectively, also vomited. Vomiting was treated with anti-emetics more often than nausea only. In most cases, nausea assessment was mild with no differences in median nausea scores (calculated for patients with nausea) between surgical departments. Following factors as predictors of the incidence of nausea among adult patients: gender, previous experience of postoperative nausea and vomiting, duration of surgery, history of motion sickness, smoking, use of opioids postoperatively, type of anaesthetic, obesity and history of migraine.

When the outcome was vomiting gender, previous experience of post- operative nausea and vomiting, duration of surgery, history of motion sickness and smoking also as the five strongest predictors in the same order as for nausea.

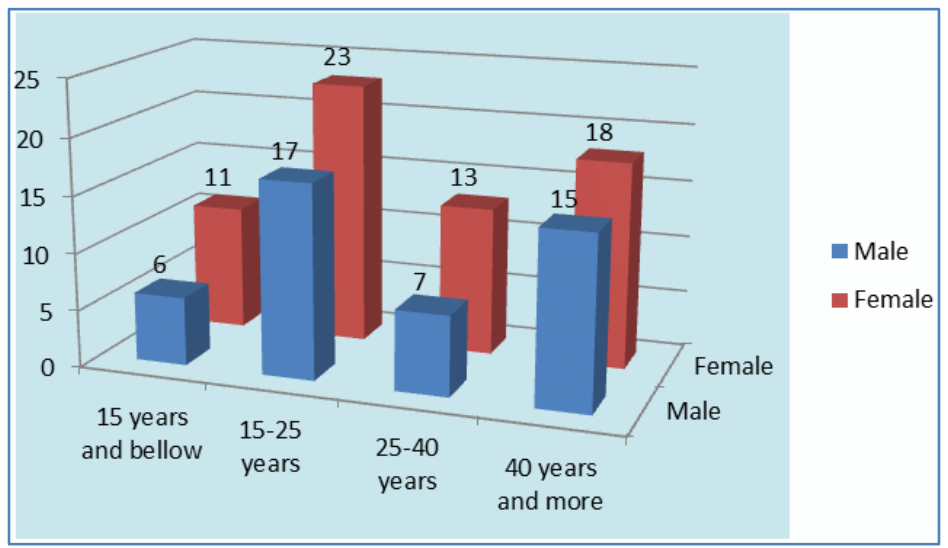

Fig-1: Age and sex distribution of the study participants $(n=110)$ 


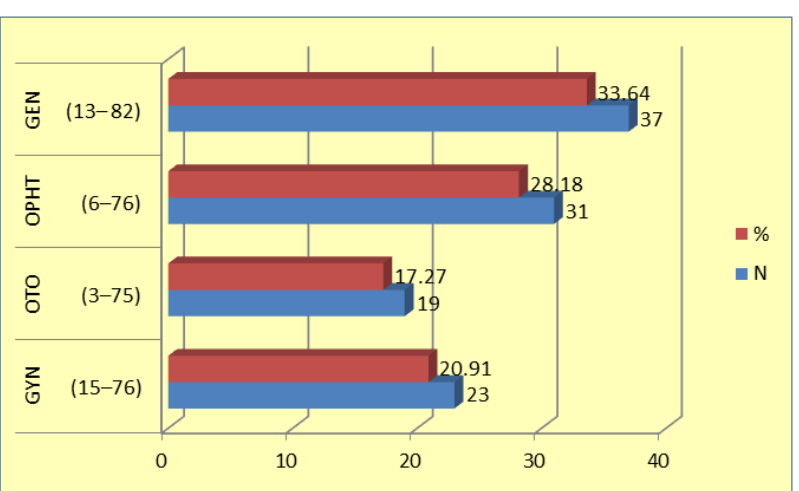

Fig-2: Demographic data of the study participant's in different types of surgery and anesthesia (n=110)

Table-1: Demographic data of the patients for the different types of surgery and anesthesia $(n=110)$

\begin{tabular}{|c|c|c|c|c|c|c|c|c|c|c|}
\hline \multirow{2}{*}{ Characteristic } & \multicolumn{2}{|c|}{ GYN (\%) } & \multicolumn{2}{c|}{ OTO (\%) } & \multicolumn{2}{c|}{ OPHT (\%) } & \multicolumn{2}{c|}{ GEN (\%) } & \multicolumn{2}{c|}{ Total } \\
\cline { 2 - 12 } & $\mathbf{N}$ & $\mathbf{\%}$ & $\mathbf{N}$ & $\mathbf{\%}$ & $\mathbf{N}$ & $\mathbf{\%}$ & $\mathbf{N}$ & $\mathbf{\%}$ & $\mathbf{N}$ & $\mathbf{\%}$ \\
\hline Current daily smokers & 1 & 0.91 & 3 & 2.73 & 4 & 3.64 & 5 & 4.55 & 13 & 11.82 \\
\hline History of migraine & 2 & 1.82 & 2 & 1.82 & 1 & 0.91 & 2 & 1.82 & 7 & 6.36 \\
\hline in childhood only & 3 & 2.73 & 1 & 0.91 & 1 & 0.91 & 1 & 0.91 & 6 & 5.45 \\
\hline as adult also & 5 & 4.55 & 5 & 4.55 & 2 & 1.82 & 1 & 0.91 & 13 & 11.82 \\
\hline Previous GA & 2 & 1.82 & 3 & 2.73 & 1 & 0.91 & 4 & 3.64 & 10 & 9.09 \\
\hline in previous GA & 4 & 3.64 & 3 & 2.73 & 5 & 4.55 & 3 & 2.73 & 15 & 13.64 \\
\hline Previous RA & 13 & 11.82 & 9 & 8.18 & 2 & 1.82 & 2 & 1.82 & 26 & 23.64 \\
\hline median & 5 & 4.55 & 2 & 1.82 & 1 & 0.91 & 2 & 1.82 & 10 & 9.09 \\
\hline Use of postoperative opioids & 2 & 1.82 & 3 & 2.73 & 2 & 1.82 & 3 & 2.73 & 10 & 9.09 \\
\hline Total & $\mathbf{3 7}$ & $\mathbf{3 3 . 6 4}$ & $\mathbf{3 1}$ & $\mathbf{2 8 . 1 8}$ & $\mathbf{1 9}$ & $\mathbf{1 7 . 2 7}$ & $\mathbf{2 3}$ & $\mathbf{2 0 . 9 1}$ & $\mathbf{1 1 0}$ & $\mathbf{1 0 0}$ \\
\hline
\end{tabular}

Table-2: Distributions of procedures (Departments) of surgery among study participants (n=110)

\begin{tabular}{|c|c|c|c|c|c|r|r|}
\hline \multirow{2}{*}{ Department } & \multirow{2}{*}{ Procedure } & \multicolumn{2}{|c|}{ Male } & \multicolumn{2}{|c|}{ Female } & \multicolumn{2}{|c|}{ Total } \\
\cline { 3 - 8 } & & $\mathbf{N}$ & $\mathbf{\%}$ & $\mathbf{N}$ & $\mathbf{\%}$ & \multicolumn{1}{|c|}{$\mathbf{~}$} & \multicolumn{1}{|c|}{} \\
\hline \multirow{3}{*}{ Gynaecology \& Intra-abdominal } & Laparoscopy & 4 & 3.64 & 17 & 15.45 & 21 & 19.09 \\
\cline { 2 - 8 } & Laparotomy & 5 & 4.55 & 13 & 11.82 & 18 & 16.36 \\
\cline { 2 - 8 } & Vaginal surgery & 0 & 0.00 & 2 & 1.82 & 2 & 1.82 \\
\hline \multirow{3}{*}{ Otolaryngology } & Tonsillectomy & 2 & 1.82 & 6 & 5.45 & 8 & 7.27 \\
\cline { 2 - 8 } & Nose and sinus surgery & 5 & 4.55 & 2 & 1.82 & 7 & 6.36 \\
\cline { 2 - 7 } & Aural surgery & 1 & 0.91 & 1 & 0.91 & 2 & 1.82 \\
\hline \multirow{2}{*}{ Ophthalmology } & Strabismus surgery & 2 & 1.82 & 1 & 0.91 & 3 & 2.73 \\
\cline { 2 - 8 } & Intra-ocular surgery & 3 & 2.73 & 3 & 2.73 & 6 & 5.45 \\
\hline General surgery & Cornea surgery & 4 & 3.64 & 5 & 4.55 & 9 & 8.18 \\
\hline \multirow{3}{*}{ Orthopaedic: } & Joint replacement & 4 & 3.64 & 3 & 2.73 & 7 & 6.36 \\
\cline { 2 - 8 } & Lower limb surgery & 8 & 7.27 & 4 & 3.64 & 12 & 10.91 \\
\cline { 2 - 8 } & Upper limb surgery & 3 & 2.73 & 3 & 2.73 & 6 & 5.45 \\
\cline { 2 - 8 } & Spinal surgery & 6 & 5.45 & 3 & 2.73 & 9 & 8.18 \\
\hline Total & & $\mathbf{4 7}$ & $\mathbf{4 2 . 7 3}$ & $\mathbf{6 3}$ & $\mathbf{5 7 . 2 7}$ & $\mathbf{1 1 0}$ & $\mathbf{1 0 0}$ \\
\hline
\end{tabular}

Table-3: Distribution of episodes with nausea and vomiting in different types of surgery $(\mathrm{n}=110)$ Type of Surgery

\begin{tabular}{|l|l|l|l|l|l|}
\hline \multicolumn{7}{|c|}{ 0-2 hours in the recovery room } \\
\hline & GYN (\%) & OTO (\%) & OPHT (\%) & GEN (\%) & Average \\
\hline Nausea & 42 & 21 & 19 & 27 & $27.25 \%$ \\
\hline Vomiting & 19 & 14 & 8 & 12 & $13.25 \%$ \\
\hline \multicolumn{7}{|c|}{$\mathbf{2 - 2 4}$ hours on ward } \\
\hline Nausea & 60 & 41 & 36 & 37 & $43.50 \%$ \\
\hline Vomiting & 31 & 21 & 13 & 22 & 21.75 \\
\hline \multicolumn{7}{|c|}{ Overall } \\
\hline Nausea & 82 & 62 & 55 & 64 & $65.75 \%$ \\
\hline Vomiting & 50 & 35 & 21 & 34 & $35.00 \%$ \\
\hline
\end{tabular}


Table-4: The distribution (\%) of the severity of nausea as assessed by the patients on the ward (2-24 h), by the type of surgery, anaesthetic technique and gender $(n=110)$

\begin{tabular}{|l|l|l|l|l|}
\hline \multicolumn{7}{|c|}{ Nausea Score } \\
\hline & none & mild & moderate & severe \\
\hline Type of Surgery \\
\hline Gynaecological & 40 & 29 & 21 & 10 \\
\hline Otolaryngological & 49 & 24 & 16 & 11 \\
\hline Ophthalmological & 64 & 15 & 16 & 5 \\
\hline General surgical & 54 & 23 & 16 & 7 \\
\hline \multicolumn{7}{|c|}{ Type of anesthesia } \\
\hline General & 48 & 25 & 18 & 9 \\
\hline Regional & 62 & 20 & 11 & 7 \\
\hline \multicolumn{7}{|c|}{ Gender } \\
\hline Male & 68 & 17 & 11 & 4 \\
\hline Female & 43 & 27 & 20 & 10 \\
\hline
\end{tabular}

\section{DiscuSSION}

This survey was designed to investigate the magnitude of postoperative nausea and vomiting. Our findings indicate that the occurrence of nausea and vomiting is still surprisingly high, especially on the general ward. Although the incidence of nausea was high but the proportion of severe nausea was generally below $10 \%$. About half of the patients with nausea also vomited. This study was conducted by personally interviewing all the subjects during the first postoperative day while still in hospital. The patients were questioned regarding their symptoms, mostly by the same investigator, in a consistent manner. The intensity of nausea, as perceived by the patient, can be measured only by a subjective scale and the same approach was chosen as with pain evaluation [7, 8]. These aspects in measurements might elicit the true proportion of patients with emetic symptoms and are in accordance with the study conducted by Cohen et al. [3]. In interpreting our results some factors must be taken into consideration. The proportion of females was twice that of males and men generally are less susceptible to nausea [1-4]. The proportion of gynaecological patients contributed to the imbalance of gender distribution, as well as to the high overall rate of nausea. Similar findings have been described recently $[3,4,9]$. Severe nausea was more common in females, who were also far more often treated with antiemetic than were men. Seventy-four per cent of our patients were operated upon under general anaesthesia, which is known to provoke more emetic reactions than doe's regional anaesthesia $[2,4]$. This may have increased the overall incidence of postoperative nausea and vomiting although the anaes- thetic techniques used were representative of current practice elsewhere. In this population, the incidence of nausea and vomiting after regional anaesthesia (mostly spinal) was greater than that reported by Carpenter et al. [10]. Over one-third of our nauseated patients associated the sensation with movement, either active or passive. Kamath et al. reported that $66 \%$ of their patients who could identify a cause for postoperative nausea blamed movement [11]. Muir et al. suggested that the increase in postoperative nausea and vomiting after leaving the recov- ery room might be related to patient transport [12]. Opioids are considered to sensitise the vestibular organ to movement-induced emesis [2, 13]. According to Andersen \& Krohg [14], opioids are seldom the cause of postoperative nausea if the patient is immobile. They also pointed out that nausea frequently accompanied pain in the early postoperative period and the relief of pain with opioids resulted in relief of nausea as well. Quinn et al. reported significantly higher mean pain scores in nau- seated patients [4].Our survey confirmed female gender, a history of previous postoperative emetic sequelae and a history of motion sickness as the most important patient-related risk factors for postoperative nausea and vomiting. These items were also included in the risk score model of Palazzo \& Evans [6] developed for a specific patient group undergoing minor orthopaedic surgery. In addition, we found smoking and the duration of operation among the five most important determinants of postoperative nausea and vomiting not considered by Palazzo \& Evans. On the other hand, their strongest individual predictor was the use of opioids in postoperative pain management, which was the sixth predictor in our analysis. In spite of the differences in the study populations and items included in the prediction model, the performance of the score of Palazzo \& Evans was only slightly worse than ours. We were not able to detect any clear effect of age on nausea but, in females, increasing age was associated with some increased risk. Our sample of children was far too small to draw any conclusions about the incidences of postoperative nausea and vomiting. Smokers had a decreased risk of nausea and vomiting, a fact also observed by Cohen et al. [3].

\section{Limitations of the study}

The study conducted in a single community. Also, our sample size was too small to exclude chance variation so; study results may not reflect the scenarios of the whole country. Our practice of using opioids and sedatives in association with some regional blocks may also have contributed to the unexpectedly. 


\section{CONCLUSION AND}

\section{RECOMMENDATIONS}

Management of postoperative nausea and vomiting is important in public health practitioners as well as policy makers. The highest incidence of emetic sequelae was observed in gynaecological patients. The most important predictive factors associated with an increased risk for nausea and vomiting were female gender, a previous history of postoperative sickness; a longer duration of surgery and a history of motion sickness. This survey does not support the current clinical impression of a decreased incidence of postoperative nausea and vomiting after surgery. However, this survey has enhanced our awareness of postoperative sickness and raised the possibility of recognizing patients at risk for nausea pre-operatively. Applying risk scoring in order to improve the patient outcome, anti-emetics given prophylactically to patients with a high probability of emesis could prevent or at least reduce these adverse symptoms.

Funding: No funding sources

Conflict of interest: None declared

Ethical approval: The study was approved by the Institutional Ethics Committee

\section{REFERENCES}

1. Lerman J. Surgical and patient factors involved in postoperative nausea and vomiting. British Journal of Anaesthesia. 1992; 69 (Suppl. 1): 24-32.

2. Watcha MF, White PF. Postoperative nausea and vomiting. Its etiology, treatment and prevention. Anesthesiology. 1992; 77: 162-84.

3. Cohen MM, Duncan PG, Deboer DP, Tweed WA. The postoperative interview: assessing risk factors for nausea and vomiting. Anesthesia and Analgesia. 1994; 78: 7-16.

4. Quinn AC, Brown JH, Wallace PG, Asbury AJ. Studies in postoperative sequelae. Nausea and vomiting - still a problem. Anaesthesia. 1994; 49: $62-5$.
5. Hanley JA, Mcneil BJ. The meaning and use of the area under an ROC curve. Radiology. 1982; 143: 29-36.

6. Palazzo M, Evans R. Logistic regression analysis of fixed patient factors for postoperative sickness: a model for risk assessment. British Journal of Anaesthesia. 1993; 70: 135-40.

7. Melzack R, Rosberger Z, Hollingsworth ML, Thirlwell M. New approaches to measuring nausea. Canadian Medical Association Journal. 1985; 133: 755-8.

8. Korttila K. The study of postoperative nausea and vomiting. British Journal of Anaesthesia 1992; 69 (Suppl. 1): 20-3.

9. Larsson S, Lundberg D. A prospective survey of postoperative nausea and vomiting with special regard to incidence and relations to patient characteristics, anesthetic routines and surgical procedures. Acta Anaesthesiologica Scandinavica 1995; 39: 539-45.

10. Carpenter RL, Caplan RA, Brown DL, Stephenson $\mathrm{C}, \mathrm{Wu} \mathrm{R}$. Incidence and risk factors for side effects of spinal anesthesia. Anesthesiology. 1992; 76 906-16.

11. Kamath B, Curran J, Hawkey C. Anaesthesia, movement and emesis. British Journal of Anaesthesia. 1990; 64: 728-30.

12. Muir JJ, Warner MA, Offord KP, Buck CF, Harper JV, Kunkel SE. Role of nitrous oxide and other factors in postoperative nausea and vomiting: a randomized and blinded prospective study. Anesthesiology. 1987; 66: 513-8.

13. Rabey PG, Smith G. Anaesthetic factors contributing to postoperative nausea and vomiting. British Journal of Anaesthesia. 1992; 69 (Suppl. 1): 40-5.

14. Andersen R, Krohg K. Pain as a major cause of postoperative nausea. Canadian Anaesthetists' Society Journal. 1976; 23: 366-9.

15. Haigh CG, Kaplan LA, Durham JM, Dupeyron JP, Harmer M, Kenny GNC. Nausea and vomiting after gynaecological surgery: a meta-analysis of factors affecting their incidence. British Journal of Anaesthesia. 1993; 71: 517-22. 